the only instances of its failures I can remember were complicated with laryngeal and tracheal effusions or were primarily cases of membranous croup. It always appeared to me that this solution, which is a most powerful antiseptic, has both $a$ topical and general effect in neutralising the diphtheritic poison, as it not only hastens the detachment of membrane from the throat, but it appears to lessen the chances of secondary affections, whether in the form of paralysis or renal incompetence. $\mathrm{Ba}^{t}$ for these effects to be obtained it is necessary that the solution should be freely and frequently administered, so as to keep the fauces as nearly as possible aseptic. And with the same view I have always used sulphurous acid or solutions of carbolic acid either as a spray or to swab the throat with. My estimate of the value of euchlorine in diphtheria is supported by the testimony of Mr. T. Schollick, who was for several years medical officer of the Isolation Hospital for this cnion, and who had opportunities of testing its effects during more than one severe epidemic of this disease. It may seem late to propose a remedy for diphtheria in the face of the remarkable results obtained by the use of antitoxin, which vossesses the advantage of controlling the laryngeal and tracheal affections, so often a cause of fatality. But circumstances may even yet arise to render a substitute for the cerum a not unwelcome addition to our resources.

I am, Sirs, your obedient servant,

Guildford, Feb. 5th, 1895 . HeNRY TAYLOR.

\section{"ENUCLEATION OF HYDATID CYST OF} LIVER:"

To the Editors of THE LANCET.

SIRS,-While conzratulating Mr. Morgan on the satisfactory result in the case of hydatid cyst of the liver published in Tre LANCET of Feb. 9th, I am anxious to araw attention to a method of treating these cases which 4 believe to be an advance on that followed in Mr. Morgan's case. In a paper published in $1891,{ }^{1}$ and again in January this year, I explained the method of treating all cysts which are not suppurating by incision, evacuation of the contents, and parasitic cyst only, and closure of the abdominal wound without drainage. By simply removing the daughter cysts and the parasitic endocyst, which has no organic connexion with the adventitious cyst, and by not making any attempt to remove or separate from surxounding parts the latter fibrous investment, the danger of momorrage is entirely avoided. No doubt some omental cysts can be removed with the fibrous cyst entire, but this should not be attempted in liver cysts. Although this method seems after four years to be but yet little practised in England, it has been extensively adopted in Anstralia, and from your Australian Correspondent's account of the Medical Society of Victoria's meeting, reported in THe LANCET of Fifeb. 9th, it would appear, successfully. No doubt it is not always necessary, except in the case of very large cysts, to invert and suture the adventitia as I originally suggested; meither is it, I think, desirable to anchor the evacuated cyst to the parietal peritoneum, as adrocated by some Australian surgeons, unless any accidental contamination should have occurred at the operation.-I am, Sirs, yours faithfully,

King-street, Leicester, Feb. 11th, 1895.

C. J. BOND.

\section{AN APPEAL}

\section{To the Editor? of THE LANCET.}

SIRs, -I desire to make an appeal to the profession on Wehalf of Mrs. Julia Guthrie, who is a widow of the late Professor Guthrie, at one time President of the Royal Sollege of Surgeons. Mrs. Guthrie was married at St. Ann's, Soho, early in 1856, and was left a widow in that jear with one son, who has since died. Mrs. Gathrie was left on the - Jeath of her husband unprovided for, but the son was during his lifetime assisted by members of the family. For many years Mrs. Guthrie bas been deperdent upon her relatives, who have now all died, and she is left alone in the world. A few months ago I was instrumental in tobtaining a pension of $£ 18$ per annum for Mrs. Guthrie from the British Medical Benevolent Fund, which at the present coment is sufficient to pay for her one room. It is desired to make a provision for her life of the very moderate sum of $£ 1$ per week, and as Mrs. Gathrie is nearly seventy-five

I Brit. Med. Jour., April 7th, 1891. years of age I confidently appeal to the profession to assist in this charity. An account bas been arranged at the Carital ard Counties Bank (bead office, Threadneedle-street, E.C.) and any subscription can be paid to them to the "Guthrie Relief Fand" or to the honorary secretary, Mr. R. Brandretb, LL.D., solicitor, 2, Dake-street, Brighton, of whom any further particulars of Mrs. Guthrie's sad case can be obtained. I am, Sirs, yours obediently.

ALFRED UPTON, L.R.C.P.Lond.. M.R.C.S.Eng.

Lansdowne-place, Hore, Brighton, Feb. 13th, 1895.

\section{"FILARIA LOA"}

To the Editors of THw LANCET.

SIRS, - With reference to the filaria loa described in THE LANCE $\mathrm{r}$ of Oct. $27 \mathrm{ch}, 1894$, supposed to be found only in Africa, I would mention the following case. A few weeks ago a horse was brought to me with a filaria moving rapidly about in the ante-chamber of its left eye. The filaria appeared about an inch and a half long, tapering at one end, blunt at the other. I ordered some perchloride of mercury solution to be injected through the cornea to kill it. Unfortunately for the specimen, but fortunately for the borse, when the aqueous escaped through the puncture the filaria also wriggled through, fell on the ground, and was lost, as I was not informed of the result in time to search for it.

I am, Sirs, yours faithfully,

Mission Hospital, Kashmir, Jan. 7th, 1895. ARTHUR Neve.

\section{THE MEANS OF CULTIVATING ORGANIC} REACTIONS IN AIR AND THEIR RELATION TO ZYMOTIC DISEASE.

To the Editors of THE LANCET.

SIRS, - The indefinite nature of recorded research due to the natural difficulties of demonstrating the facts involved in atmospheric pollution by sewage is exemplified in the following statement made at a recent meeting of the London County Council regarding sewer gas in London. The Main Drainage Committee had the subject under consideration, and when they learned from the experts that sewer gas was free from germs they were very mach astonished. They had, however, referred it to the experts to say whether sewer gas was not injurious to public health "in some way" other than through the presence of bacilli. The evidence available in proof of pathogenic origin in organic reactions in air as yet is more valuable in its indications than in actual facts. The effects, however, of organic pollution in air were early noticed by me during very protracted experiments in aerifying sewage and other liquors between 1878 and 1886. These effects, regarded as distinct from odour, were always apparent during the treatment of sewage in any stage of putrefactive ferment, and as possessing a distinct bearing on a subject which I believe requires investigation on its own account.

The first actual evidence of pathogenic origin in air is supplied by the result attending the influenza irquiry in. stituted by the Local Government Board. It is simple history that a subsequent official irquiry by the Bcard attributed the malady chiefly to the presence of refractory organic impurities in the air. It was now apparent that the march of events by investjgation must soon supply the corroborating details which I felt were required to clearly indicate the direction and means by which a real demonstration of the facts might be conveniently obtained. These $d \in t a i l s$ were furnished in the highly important conclnsions advanced by Dr. Percy Frankland, F.R.S., dealing with the subject at last year's Congress of the British Association at Nottingham, which, I venture to think, afford the clue to the ultimate results of phenomena described, and also, short of demonstrating the facts, define the modification influence which operates in nature through organic reactions in air. The following quotation from Dr. Frankland's address on Bacteriology at the Congress of the British Association in 1893 contains the conclusions referred to:-1. "The science of bacteriology dates from the introduction by Koch of the method of pure cultures some twelve years ago. Microscopical determinations, at first entirely relied npon, had giren way more and more to chemical tests, but the differentiation ard identification of 'particular species' remain very difficalt, and, indeed, become more and more so." Comment is needless, beyond asking the question, Why, unless a modifying 
influence expands in sympathy with ever-increasing volume of putrefactive sewage, should identification of "particular species" remain with experience very difficult, and, indeed, become "more and more so"? 2. "By educational culture the cnaracter of an organism may be quite changed. On the other hand, the virulence can be increased, although as yet no pathogenic organism 'has been raised ' from nonpathogenic, but as 'similar modification processes ' evidently go on in nature we must grant that bacilli acquire new characteristics under new conditions." The question bere is, Does chemistry or nature itself in other direction afford ns the stady of similar conditions to those prevailing in sewers? If not, we must admit that organic life exposed to such influence must adapt its function to surroundings. How this adaptation works is the very essence of the actual demonstration required. 3. "We have real anthrax and an exceedingly similar innocuous modification, both occurring in the soil. Many toxic forms-cholera, typhus, diphtheria bacilli-have psendo-forms. In certain cases the modification may be due to the exclusion or exhanstion of oxygen. Assuming fermentation in presence of air to be normal, as in the early days of Pasteur, a modified reaction can apparently proceed when no more oxygen is at disposal, so that we have also anaerobic fermentation." We have here the modification influence defined, and also the answer to both the questions asked; whilst, as regards the influence exerted by organic impurity in air, we find that all available evidence supports the view that an actual demonstration of facts of the first importance to the medical profession and the public at large is alike possible and much to be desired.

In recent experiments made with a special form of apparatns suggested by results described I have, I believe, secured the means of convenient observation of sewage reactions in every form, produced under precisely the same natural conditions which operate in town sewers under rariable conditions of time, temperature, and air-supply. As regards the practical aspect, since the introduction of Koch's method of culture I have held the belief that by securing control of the nature of fermentation in sewage we secure the only effectual means of reducing that organic pollution of the atmosphere of populations which all available evidence proves the public interest demands. This control I have secured by means of halogen disinfection through the medium of air-supply. It will be remembered that similar means are relied upon to secure the disinfection of organic emanations escaping at manholes, \&c., connected with the system of the London main sewers. In that case sulphurous acid is, I believe, the agent employed; the cost, however, in perhaps all other cases is prohibitive. On the other hand, by using the sulphurous vapours (given off by the storage batteries used in electric supply), in conjunction with air and complete removal of the volatile byproducts of sewage, we obtain effectual control over the fermentive course, even with fluctuations in the mount of organic matter as high as 800 per cent. The fluctuations in London are doubtless of much wider range and serve to show the futility of relying on any practicable degree of aeration sufficient to meet the necessities of the case in which the oxygen required for normal course may vary in an hour between two and ten or even more grains per gallon. In such fluctuations as named we probably see the first cause of putrefactive ferment in town eewers, which ends in producing influences under which we mast grant that bacilli acquire new characteristics. It is (qually probable that with exhaustion of oxygen a modification begins by which the normal functions of organisms become changed. Pathology has taught us much regarding he life history of germs attending specific forms of disease, !nt the question still remains, How come these disease germs into existence? I am, Sirs, yours faithfully,

sueffield.

J. HiLl-HaRTLAND.

* We publish this letter in view of the interest of this sghject, bat we have been compelled to reduce the great length of the original communication.--ED. L.

THE REMLNERATION OF THE RESIDENT OFFICERS OF ST. BARTHOLOMEW'S HOSPITAL."

To the Editors of THE LANCET.

SIRs,-If you will kindly allow me a little space I should like to reply to your correspondent "Fair Pay" in the matter of his letter about the pay of the resident officers at St. Bartholomew's. What are his facts: (1) the residents get $\$ 25$ per annum; (2) during the six montbs they are in residence they have to pay for their food. These are perfectly correct, but "Fair Pay" might remember that wages or salary are regulated by the laws of supply and demand. There is no donbt that even if the residents had to pay a fee for holding the resident appointments there would be no lack. of candidates, so that under the present régime there is something to be thankful for.

Now I am certain that no one who has been on the junior staff of St. Bartholomew's will deny that the experience he gained, and, to use a colloquialism, the general good time he had, were worth far more than the $£ 50$ which he spent on his food. Whether he were in the service of the hospital or not, he would have to eat, for the average man out of whom a resident officer is made is of coarser mould than Eve Fliegen, the lady who lived on the smell of flowers. Finally, if " Fair Pay" has anything to do with St. Bartholomew's, why does not he say so? If he has not, he appears to be interfering in a matter which cannot concern him-unlese. indeed, he is the parent of a house physician or surgeon. I am, Sirs, yours faithfully,

AN OLd House SÜRgEON OF ST. BARTholomeW's

\section{LIVERPOOL}

\section{(FROM OUR OWN CORRESPONDHNT.)}

\section{The Recent Severe Weather.}

ThE severity of the frost here may be judged by the appearance of ice in the Mersey. Fourteen years ago the river was in parts frczen over, a most unusual sight, and again has this sight been witnessed. The training ships have been as icebound as if they had been in Arctic regions, and ferry steamers have had to plough their way through the ice. As many as $15^{\circ} \mathrm{F}$. of frost have been registered in the city itself, while in the suburbs an even lower temperature. has been reached.

The Medical Charities.

During the months of January and February the annual meetings of all the medical charities are held. These all show a continuation and aggravation of the state of chronic bankruptcy into which our hospitals and dispensaries are permitted to languish. The Royal Infirmary ow $€$ s its bankers $£ 3000$, the Northern Hospital owes $£ 4000$, and the Royal Southern Hospital has a balance on the wrong side of $£ 5000^{-}$ Thus a total of $£ 12,000$ will be required to free these three institutions from debt, and then the struggle between an insufficient income and a heary $\epsilon$ xpenditure will begin again. Out of the half million inhabitants of this city not more than ten thousand at the very most are annual subscribers to the medical charities. A prominent citizen remarked at the annual meeting of the Royal Southern Hospital yesterday that with a few honourable exceptions the shopkeepers did not support the charities as they deserved, and from what has just been stated it must be obvious that there is plenty of room for improvement.

The Lord Mayor and the Hospitals.

The Lord Mayor (Mr. Watts) has shown his interest in the various hospitals, not only by presiding at the annual meetings (except at the Royal Infirmary, when Lord Derby presided), but also by visiting them. In addition to the hospitals already alluded to bis lordship has visited the Hospital for Consumption and the Liverpool Fye and Kar Infirmary. These visits from the chief magistrate are very greatjy appreciated.

Salting the Streets : the Removal of Snow and the Unemployed.

The question as to whether the salting of the streets after snowstorms is or is not a desirable practice bas again come to the fore. On the one hand, it is contended that it is cruef to horses and barefooted persons, and also to the public generally, since it intensifies the coldness of the atmosphere. It is urged, on the other hand, that in such a city as this, with 300 miles of streets, it would be impossible to remove the snow in any other way. The usual scavenging staff was augmented by casual helper, but only a very small proportion of the number required applied out of the alleged large number of unemployed. It is to be feared that too many of these men prefer idling and hawking their grievances in the streets to honest efforts to obtain work, forgetting or ignoring that such conduct may end in a reappearance of typhus fever. 